\title{
Evaluating agricultural water-use efficiency based on water footprint of crop values: a case study in Xinjiang of China
}

\author{
HAI Yang ${ }^{1}$, LONG Aihua ${ }^{1,2^{*}}$, ZHANG Pei ${ }^{1}$, DENG Xiaoya ${ }^{1}$, LI Junfeng ${ }^{2}$, DENG Mingjiang ${ }^{3}$ \\ ${ }^{1}$ State Key Laboratory of Simulation and Regulation of Water Cycle in River Basin, China Institute of Water Resources and \\ Hydropower Research, Beijing 100038, China; \\ ${ }^{2}$ College of Water Conservancy and Architectural Engineering, Shihezi University, Shihezi 832003, China; \\ ${ }^{3}$ Xinjiang Water Conservancy and Hydropower Planning and Design Management Bureau, Urumqi 830000, China
}

\begin{abstract}
Efficient agricultural water use is crucial for food safety and water conservation on a global scale. To quantitatively investigate the agricultural water-use efficiency in regions exhibiting the complex agricultural structure, this study developed an indicator named water footprint of crop values (WFV) that is based on the water footprint of crop production. Defined as the water volume used to produce a unit price of crop $\left(\mathrm{m}^{3} / \mathrm{CNY}\right)$, the new indicator makes it feasible to directly compare the water footprint of different crops from an economic perspective, so as to comprehensively evaluate the water-use efficiency under the complex planting structure. On the basis of WFV, the study further proposed an indicator of structural water-use coefficient (SWUC), which is represented by the ratio of water-use efficiency for a given planting structure to the water efficiency for a reference crop and can quantitatively describe the impact of planting structure on agricultural water efficiency. Then, a case study was implemented in Xinjiang Uygur Autonomous Region of China. The temporal and spatial variations of WFV were assessed for the planting industries in 14 prefectures and cities of Xinjiang between 1991 and 2015. In addition, contribution rate analysis of WFV for different prefectures and cities was conducted to evaluate the variations of WFV caused by different influencing factors: agricultural input, climatic factors, and planting structure. Results from these analyses indicated first that the average WFV of planting industries in Xinjiang significantly decreased from $0.293 \mathrm{~m}^{3} / \mathrm{CNY}$ in 1991 to 0.153 $\mathrm{m}^{3} / \mathrm{CNY}$ in 2015 , corresponding to an average annual change rate of $-3.532 \%$. WFV in 13 prefectures and cities (with the exception of Karamay) has declined significantly during the period of 1991-2015, indicating that agricultural water-use efficient has effectively improved. Second, the average SWUC in Xinjiang decreased from 1.17 to $1.08 \mathrm{~m}^{3} / \mathrm{CNY}$ in the $1990 \mathrm{~s}$, and then declined to $1.00 \mathrm{~m}^{3} / \mathrm{CNY}$ in $2011-2015$. The value of SWUC was highly consistent with the relative value of WFV in most prefectures and cities, showing that planting structure is one of the primary factors affecting regional agricultural water-use efficiency. Third, the contribution rate of WFV variations from human factors including agricultural input and planting structure was much more significant than that from climatic factors. However, the distribution of agricultural input and the adjustment of planting structure significantly differed among prefectures and cities, suggesting regional imbalances of agricultural development. This study indicated the feasibility and effectiveness of controlling agricultural water use through increasing technical input and rational selection of crops in the face of impending climate change. Specifically, we concluded that, the rational application of chemical fertilizers, the development of the fruit industry, and the strict restriction of the cotton industry should be implemented to improve the agricultural water-use efficiency in Xinjiang.
\end{abstract}

\footnotetext{
"Corresponding author: LONG Aihua (E-mail: ahlong@iwhr.com)

The first and second authors contributed equally to this work.

Received 2019-10-13; revised 2020-02-27; accepted 2020-04-27

C Xinjiang Institute of Ecology and Geography, Chinese Academy of Sciences, Science Press and Springer-Verlag GmbH Germany, part of Springer Nature 2020
} 
Keywords: agricultural input; climatic factors; contribution rate; planting structure; structural water-use coefficient; water footprint of crop values

Citation: HAI Yang, LONG Aihua, ZHANG Pei, DENG Xiaoya, LI Junfeng, DENG Mingjiang. 2020. Evaluating agricultural water-use efficiency based on water footprint of crop values: a case study in Xinjiang of China. Journal of Arid Land, 12(4): 580593. https://doi.org/10.1007/s40333-020-0058-x

\section{Introduction}

The scarcity and degradation of fresh water resources have led to threats toward food security and the sustainable development of human society. Specifically, these threats arise from a number of factors including the allocation, utilization, and management of water resources, in addition to continuous population growth and climate change (He et al., 2020; Zahra et al., 2020). Agricultural activity, which plays a key role in ensuring the food security and welfare for $7.4 \times 10^{9}$ people (Piao et al., 2010), is the largest single consumer of fresh water globally, accounting for $70 \%$ of current water used by humans (Calzadilla et al., 2010; Chu et al., 2017). Consequently, improving the efficiency of agricultural water use is critical to water-food security, and this is particularly crutial for vast arid and semi-arid areas where water resources play a controlling role (Du et al., 2015). For this purpose, a deep understanding of water-use efficiency is an essential preliminary work (Hassan and Olbrich, 1999), which is also the main concern of our current research.

Agricultural water-use efficiency (AWUE) has drawn great attentions of researchers worldwide. The current widely accepted definition of AWUE is the ratio of crop yield to the amount of water consumed for crop growth (Sinclair et al., 1984; Howell, 2001), which is equivalent to transpiration evapotranspiration (Apurupa et al., 2019), or the total water input towards crop production (Fan et al., 2014; Gilbert et al., 2019; Ma et al., 2019; Wang et al., 2019). Due to the diversification of agricultural water assessment objectives, the AWUE index exhibits a growing inadequacy, primarily due to the lack of distinction between green water (precipitation consumed for crop growth) and blue water (water appropriated from surface or groundwater sources).

The indicator of water footprint (WF) was introduced by Hoekstra and Hung (2002) and further developed by Hoekstra and Chapagain (2008). The WF of a product refers to the total volume of fresh water that is consumed across the full supply chain of production (Hoekstra et al., 2009). This measurement comprises three components: green water footprint $\left(\mathrm{WF}_{\text {green }}\right)$, blue water footprint (WF $\mathrm{Wlue}_{\text {blu }}$, and grey water footprint $\left(\mathrm{WF}_{\text {grey }}\right.$; the volume of water required to assimilate the pollutant load generated in the production process) (Mekonnen and Hoekstra, 2010). In particular, blue water is the principal portion by which agricultural sector competes with other water-use sectors and largely depends on the local water allocation schedule (Ridoutt and Pfister, 2010; Lu et al., 2016). In other words, the WF indicator reflects not only the volume of water used, but also its components and environmental impacts, making it a comprehensive indicator of water resources utilization compared to the restricted estimation of water withdrawal. The most widely used WF indicator for AWUE evaluation is water footprint of crop production $\left(\mathrm{WF}_{\mathrm{c}} ; \mathrm{m}^{3} / \mathrm{kg}\right)$, which is commonly expressed as the water volume used to produce a unit of crop product (Lovarelli et al., 2016). A large amount of studies have investigated the $\mathrm{WF}_{\mathrm{c}}$ of various crops (Chapagain and Orr, 2009; Bulsink et al., 2010; Rodriguez et al., 2015; Pellegrini et al., 2016), including rice (Chapagain et al., 2011; Yoo et al., 2014; Marano et al., 2015), wheat (Mekonnen and Hoekstra, 2010; Sun et al., 2013a; Mekonnen and Hoekstra, 2014), maize (Bocchiola et al., 2013; Nana et al., 2014), cotton (Chapagain et al., 2006; Aldaya et al., 2010), etc. The majority of these researches have focused on the $\mathrm{WF}_{\mathrm{c}}$ of a specific crop, while some of them have explored the possible driving factors affecting the $\mathrm{WF}_{\mathrm{c}}$, such as climate change and agricultural input (Sun et al., 2013a, b), providing a theoretical basis for addressing climate change and improving AWUE.

Although $\mathrm{WF}_{\mathrm{c}}$ does exhibit notable advantages in evaluating the AWUE of specific crops, the $\mathrm{WF}_{\mathrm{c}}$ values of different crops are infeasible to be directly compared, consequently limiting the effectiveness of the index in estimating comprehensive AWUE in areas with complex planting structure. In order to make up for this deficiency, we proposed an index termed the "water footprint of crop values" (WFV) that is defined as the water volume used to produce the unit price of a crop 
$\left(\mathrm{m}^{3} / \mathrm{CNY}\right)$. The developed index improves the economic interpretations of WF and enables the direct comparison of WF among different crops; thereby the comprehensive economic efficiency of AWUE under different types of planting structure can be measured. On the basis of WFV, we also defined a quantitative indicator termed the "structural water-use coefficient" (SWUC), which is represented by the ratio of WFV for a given planting structure to the WFV when using a single crop (reference crop). Through these two indicators, we established a quantitative relationship between WF and planting structure, providing an intuitive basis for regional planting structure adjustment and AWUE improvement.

The specific objectives of this study are to (1) estimate the WFV of different crops including wheat, rice, maize, cotton, soybean, sugar crops, oil crops, fruits, and vegetables (covering $95.92 \%$ of the total cultivation area in Xinjiang Uygur Autonomous Region of China in 2015) in 14 prefectures and cities of Xinjiang during 1991-2015; (2) analyze the temporal and spatial variations in WFV; and (3) investigate the factors influencing WFV variations from three aspects including agricultural investment, meteorological factors, and planting structure. Based on all these works, we recommended the effectiveness and superiority of WFV in the evaluation of AWUE.

\section{Data and methods}

\subsection{Study area}

Xinjiang Uygur Autonomous Region is located in northwestern China, covers an area of $1.66 \times 10^{6}$ $\mathrm{km}^{2}$ and consists of 14 prefectures and cities. Due to its long distance from the ocean, Xinjiang shows a typical semi-arid and arid climate (Chen et al., 2010). The Tianshan Mountains located in the central part divide the region into northern Xinjiang (Altay, Tacheng, Karamay, Bortala, Changji, Urumqi, and Ili) (Wu et al., 2015) and southern Xinjiang (Kizilsu, Kashgar, Aksu, Hotan, and Bayingol) (Fig. 1). Northern Xinjiang features a semi-arid climate with a mean annual precipitation of $210 \mathrm{~mm}$, while southern Xinjiang exhibits a continental dry climate with a mean annual precipitation of less than $100 \mathrm{~mm}$. Besides, Turpan and Hami belong to eastern Xinjiang, representing the driest region of China with a mean annual precipitation of less than $50 \mathrm{~mm}$ (Xu et al., 2010; Li et al., 2011). Due to the harsh climatic conditions, water shortage is the main bottleneck restricting economic development and environmental conservation in Xinjiang. Agriculture is the pillar industry in Xinjiang, which consumed $54.1 \times 10^{9} \mathrm{~m}^{3}$ of fresh water in 2015 , accounting for $93.70 \%$ of the total water consumption.

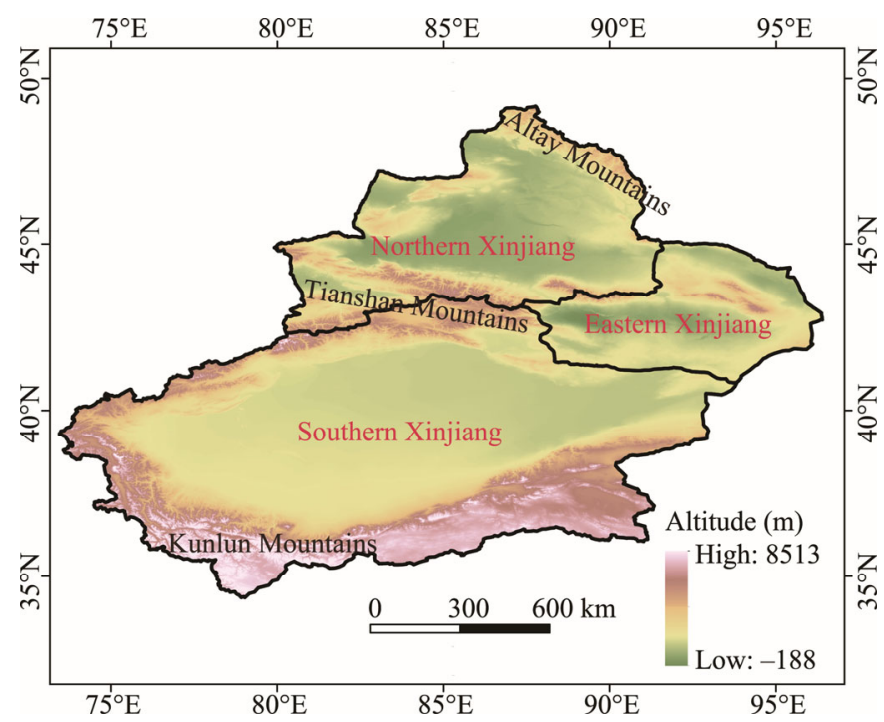

Fig. 1 Overview of northern Xinjiang (Altay, Tacheng, Karamay, Bortala, Changji, Urumqi, and Ili), southern Xinjiang (Kizilsu, Kashgar, Aksu, Hotan, and Bayingol), and eastern Xinjiang (Turpan and Hami) 


\subsection{Data sources}

The climate data during 1991-2015 used in this study were downloaded from 88 weather stations of the National Meteorological Center in Xinjiang, including annual precipitation $(\mathrm{mm})$, annual sunshine hours $(\mathrm{h})$, average wind speed $(\mathrm{km} / \mathrm{d})$, relative humidity $(\%)$, maximum temperature $\left({ }^{\circ} \mathrm{C}\right)$, minimum temperature $\left({ }^{\circ} \mathrm{C}\right)$, and average temperature $\left({ }^{\circ} \mathrm{C}\right)$. Agricultural production data were obtained from Xinjiang Statistical Yearbook (Bureau of Statistics of Xinjiang Uygur Autonomous Region, 1991-2015) and Xinjiang Production and Construction Corps Statistical Yearbook (Bureau of Statistics of Xinjiang Production and Construction Corps, 1991-2015). Agricultural data included crop area $\left(\mathrm{hm}^{2}\right)$ and crop yield $(\mathrm{t})$ of the major crops within each prefecture or city. Agricultural technology input data comprised the total power of agricultural machinery $\left(\mathrm{kw} / \mathrm{hm}^{2}\right)$ and the amount of nitrogen $(\mathrm{N})$ fertilizer utilization $\left(\mathrm{kg} / \mathrm{hm}^{2}\right)$. Agricultural product price data were obtained from the Statistical Yearbook of China (National Bureau of Statistics of China, 2015) and a constant price was estimated and used.

\subsection{WFV calculation}

The green and blue water footprints $\left(\mathrm{WF}_{\text {green }}\right.$ and $\mathrm{WF}_{\text {blue }}$, respectively) were calculated using FAO's CROPWAT model as recommended by Hoekstra et al. (2009) and Sun et al. (2016). As for the WF grey, we regarded the $\mathrm{N}$ fertilizers as the main pollutant and calculated the $\mathrm{WF}_{\text {grey }}$ using the following Equation (Mekonnen and Hoekstra, 2010):

$$
\mathrm{WF}_{\text {grey }(i, j)}=\frac{\alpha \times \mathrm{AR}_{i, j}}{\mathrm{C}_{\text {max }}-\mathrm{C}_{\text {nat }}},
$$

where $\mathrm{WF}_{\text {grey }(i, j)}\left(\mathrm{m}^{3} / \mathrm{kg}\right)$ is the grey water footprint of crop $i$ produced in prefecture or city $j$, which is calculated separately for the nine major crops (wheat, maize, rice, cotton, soybean, oil crops, sugar crops, fruits, and vegetables) in the 14 prefectures and cities; $\alpha(\%)$ is the leaching fraction that is assumed to be $10 \%$ of the applied $\mathrm{N}$ fertilizers; $\mathrm{AR}_{i, j}\left(\mathrm{~kg} / \mathrm{hm}^{2}\right)$ is the net amount of $\mathrm{N}$ fertilizer utilization for crop $i$ in prefecture or city $j$; and $\mathrm{C}_{\max }$ and $\mathrm{C}_{\text {nat }}$ represent the maximum acceptable concentration of nitrogen and the natural concentration of nitrogen in the receiving water body, respectively. $\mathrm{C}_{\max }$ was given the international standard of $10 \mathrm{mg} / \mathrm{L}$ and $\mathrm{C}_{\text {nat }}$ was assumed to be zero (Mekonnen and Hoekstra, 2010).

WFV was then obtained by dividing the total WF by the total crop values, as shown in Equations 2 and 3:

$$
\begin{gathered}
\mathrm{WFV}_{i, j}=\frac{\mathrm{WF}_{i, j}}{P_{i, j}}=\frac{\mathrm{WF}_{\text {green }(i, j)}+\mathrm{WF}_{\text {blue }(i, j)}+\mathrm{WF}_{\text {grey }(i, j)},}{Y_{i, j} \times p_{i}} \\
\mathrm{WFV}_{j}=\frac{\sum_{i=1}^{n} \mathrm{WF}_{i, j}}{\sum_{i=1}^{n} P_{i, j}}=\frac{\sum_{i=1}^{n}\left(\mathrm{WF}_{\text {green }(i, j)}+\mathrm{WF}_{\text {blue }(i, j)}+\mathrm{WF}_{\text {grey }(i, j)}\right)}{\sum_{i=1}^{n}\left(Y_{i, j} \times p_{i}\right)},
\end{gathered}
$$

where $\mathrm{WFV}_{i, j}\left(\mathrm{~m}^{3} / \mathrm{CNY}\right), \mathrm{WF}_{\text {green }(i, j)}\left(\mathrm{m}^{3}\right)$, and $\mathrm{WF}_{\text {blue }(i, j)}\left(\mathrm{m}^{3}\right)$ are the water footprint of crop values, green water footprint, and blue water footprint of crop $i$ produced in prefecture or city $j$, respectively; $\mathrm{WFV}_{j}\left(\mathrm{~m}^{3} / \mathrm{CNY}\right)$ is the water footprint of crop values in prefecture of city $j ; Y_{i, j}(\mathrm{~kg})$ is the crop yield of crop $i$ produced in prefecture or city $j ; p_{i}(\mathrm{CNY} / \mathrm{kg})$ is the unit price of crop $i$; and $P_{i, j}(\mathrm{CNY})$ is the total price of crops in prefecture or city $j$.

\subsection{Planting structure analysis}

The SWUC, as mentioned previously, can be calculated using the following equation:

$$
I_{j}=\sum_{i=1}^{n}\left(\frac{\mathrm{WFV}_{i, j}}{\mathrm{WFV}_{0, j}} \times \omega_{i, j}\right),
$$

where $I_{j}$ is the structural water-use coefficient in prefecture or city $j$; $\mathrm{WFV}_{i, j}\left(\mathrm{~m}^{3} / \mathrm{CNY}\right)$ is the water footprint of crop values in prefecture or city $j$; $\mathrm{WFV}_{0, j}$ is the WFV of the reference crop; and $\omega_{i, j}$ is the portion of planting area used for crop $i$ relative to the total crop planting area over prefecture or 
city $j$. In this study, wheat was chosen as the reference crop for it's widely cultivation in Xinjiang throughout the whole study period.

\subsection{Contribution of factors towards WFV variations}

In this study, we used contribution rate analysis to figure out the driving forces of WFV variations. The contribution rate analysis can assign the variations of WFV to different influence factors. First of all, based on Cobb-Douglas production function, which has been successfully applied to evaluate the contribution rate in several studies (Yang et al., 2000; Sun et al., 2013b; Zhao et al., 2014), we integrated the relationship between WFV and effect factors as follows:

$$
\mathrm{WFV}_{j}=A_{j} X_{1, j}{ }^{a_{1, j}} X_{2, j}{ }^{a_{2, j}} \cdots X_{n, j}{ }^{a_{n, j}} \text {, }
$$

where $A_{j}$ is a constant coefficient in prefecture or city $j ; X_{n, j}$ is the factor $n$ that influences $\mathrm{WFV}_{j}$ in prefecture or city $j$; and $a_{n, j}$ is the influence elasticity coefficient of factor $n$ on $\mathrm{WFV}_{j}$ in prefecture or city $j$. Through logarithmic transformation progress, a linear Equation can be obtained as follows:

$$
\ln \left(\mathrm{WFV}_{j}\right)=\ln (A)+a_{1, j} \ln \left(X_{1, j}\right)+a_{2, j} \ln \left(X_{2, j}\right)+\cdots+a_{n, j} \ln \left(X_{n, j}\right) .
$$

It should be noted that we adapted the principal component analysis to eliminate the collinearity effect between different factors ( $\mathrm{Li}$ and Chen, 2010).

At last, the contribution rate of various factors towards the variations of $\mathrm{WFV}_{j}$ can be calculated by the following equation:

$$
V_{n, j}=a_{n, j} \frac{\mathrm{d} X_{n, j} / X_{n, j}}{\mathrm{dWFV}_{j} / \mathrm{WFV}_{j}}=a_{n, j} \frac{\frac{d X_{n, j} / d t}{X_{n, j}}}{\frac{\mathrm{dWFV}_{j} / \mathrm{d} t}{\mathrm{WFV}_{j}}},
$$

where $V_{n, j}(\%)$ is the contribution rate of factor $n$ to the variations of $\mathrm{WFV}_{j} ; t$ (a) is the time period; and $\frac{d X_{n, j} / d t}{X_{n, j}}(\%)$ and $\frac{d \mathrm{WFV}_{j} / d t}{\mathrm{WFV}_{j}}(\%)$ are the average annual change rates of the factor $n$ and $\mathrm{WFV}_{j}$, respectively.

Agricultural investment, climatic factors, and planting structure were considered as the driving factors underlying WFV variations. Among these, agricultural investment comprised the total power of agricultural machinery and the consumption of $\mathrm{N}$ fertilizers, while climatic factors included precipitation, temperature, sunshine hours, wind speed, and relative humidity. Correlational analysis was used to identify impact factors that were significantly correlated to WFV, which would be further considered during model construction.

\section{Results}

\subsection{Variations in WFV among 14 prefectures and cities}

WFV of 14 prefectures and cities in Xinjiang at different time periods over 1991-2015 is shown in Figure 2. The average WFV of planting industries in Xinjiang significantly decreased from 0.293 $\mathrm{m}^{3} / \mathrm{CNY}$ in 1991 to $0.153 \mathrm{~m}^{3} / \mathrm{CNY}$ in 2015 , corresponding to an average annual change rate of $3.532 \%$. AWUE was increased effectively during the period 1991-2015.

At the regional scale, WFV varied considerably among prefectures and cities. The largest WFV, $0.812 \mathrm{~m}^{3} / \mathrm{CNY}$, was generated in Bortala during 1991-1995, while the smallest WFV with the value of $0.066 \mathrm{~m}^{3} / \mathrm{CNY}$ was observed in Urumqi during 2011-2015. WFV in most prefectures and cities was reduced generally during the study period and could be divided into three types (high, low and normal) (Fig. 2). Specifically, Bortala exhibited the highest WFV in Xinjiang, and this was especially evident in the 1990s. Although the WFV of Bortala significantly decreased from 1991 to 2015 (with an average annual change rate of $-4.035 \%$ ), it remained the largest in Xinjiang in 2015. In contrast, WFV of Ili, Urumqi, and Turpan was relatively low between 1991 and 2015. WFV of the remaining prefectures and cities decreased from $0.238-0.398 \mathrm{~m}^{3} / \mathrm{CNY}$ in the early 1990 s to $0.115-0.222$ 
$\mathrm{m}^{3} / \mathrm{CNY}$ in 2011-2015, which was consistent with the average variations observed in the whole Xinjiang. WFV in Altay and Kizilsu decreased most significantly, with average annual changes of $-6.339 \%$ and $-5.760 \%$, respectively. As an obvious exception, WFV in Karamay showed an increasing trend from 1991 to 2010 , with an average annual change rate of $2.033 \%$.

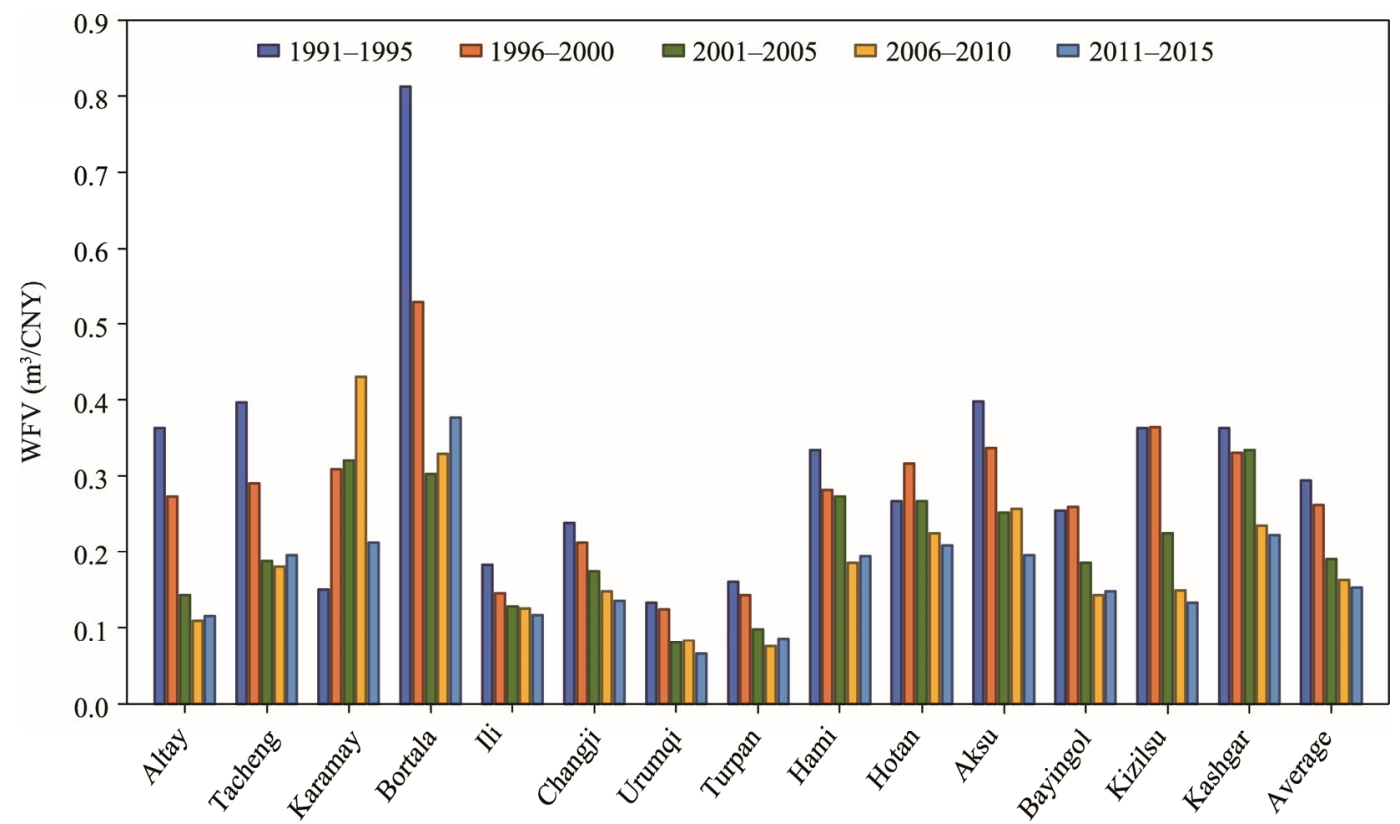

Fig. 2 Variations in water footprint of crop values (WFV) in 14 prefectures and cities of Xinjiang at different time periods from 1991 to 2015

\subsection{Spatial characteristics and variations of agricultural investment in Xinjiang}

The average agricultural machinery power per unit area of cultivated land in Xinjiang has almost doubled from $2.41 \mathrm{kw} / \mathrm{hm}^{2}$ in $1991-1995$ to $4.08 \mathrm{kw} / \mathrm{hm}^{2}$ in $2011-2015$. However, obvious regional variations were observed. As shown in Table 1, the agricultural machinery power per unit area of cultivated land in all prefectures and cities of northern Xinjiang has experienced rapid and stable development. On the contrary, in southern Xinjiang, Bayingol was the only prefecture with agricultural machinery power per unit area of cultivated land that reached the average level of Xinjiang. Although there has been a rapid development of mechanical level in southern Xinjiang from 1991 to 2015, it was still hard to reach the advanced level. The development of agricultural machinery in eastern Xinjiang was advanced in the early 1990s, but showed no significant development since then, as shown in Table 1.

The large-scale application of $\mathrm{N}$ fertilizers in Xinjiang began in 1975, resulting in significant development of crop production (Tao and Yang, 2004). The average consumption of $\mathrm{N}$ fertilizers per unit area of cultivated land increased from $175 \mathrm{~kg} / \mathrm{hm}^{2}$ in $1991-1995$ to $424 \mathrm{~kg} / \mathrm{hm}^{2}$ in $2011-2015$, with an average annual change rate of $3.754 \%$. On a regional scale, the consumption of $\mathrm{N}$ fertilizers in southern Xinjiang in the early 1990s was significantly higher than those in northern and eastern Xinjiang (Table 2). However, during the period of 2001-2015, the utilization of $\mathrm{N}$ fertilizers in northern Xinjiang increased rapidly and gradually surpassed those in southern Xinjiang. The application amount of $\mathrm{N}$ fertilizers in eastern Xinjiang was less than those in other regions and the change rate was relatively slower.

\subsection{Climatic factors}

According to the observations from major meteorological stations in Xinjiang, the average annual precipitation, average annual sunshine hours, and annual average temperature increased during the period of 1991-2015, while the annual average wind speed and relative humidity decreased. 
Table 1 Agricultural machinery power per unit area of cultivated land in 14 prefectures and cities of Xinjiang at different time periods from 1991 to 2015

\begin{tabular}{cccccccc}
\hline \multirow{2}{*}{ Region } & $\begin{array}{c}\text { Prefecture/ } \\
\text { city }\end{array}$ & \multicolumn{2}{c}{ Agricultural machinery power per unit area of cultivated land $\left(\mathrm{kw} / \mathrm{hm}^{2}\right)$} & $\begin{array}{c}\text { Average annual } \\
\text { change rate } \\
(\%)\end{array}$ \\
\cline { 3 - 6 } Northern & Altay & 3.35 & 3.64 & 4.41 & 5.82 & 5.69 & 3.197 \\
Xinjiang & Tacheng & 2.74 & 3.98 & 5.90 & 5.78 & 5.30 & 3.968 \\
& Karamay & 2.09 & 2.61 & 2.10 & 3.28 & 3.07 & 4.756 \\
& Bortala & 2.87 & 3.01 & 3.63 & 4.12 & 4.08 & 2.532 \\
& Ili & 3.62 & 4.44 & 5.76 & 6.39 & 7.26 & 3.854 \\
Eastern & Changji & 2.52 & 2.80 & 3.21 & 3.11 & 3.19 & 1.709 \\
Xinjiang & Urumqi & 6.09 & 5.80 & 6.16 & 6.52 & 9.01 & 2.987 \\
Southern & Turpan & 7.31 & 8.59 & 7.70 & 6.62 & 6.44 & -0.005 \\
Xinjiang & Hami & 3.92 & 4.63 & 5.00 & 4.46 & 4.38 & 0.004 \\
& Hotan & 1.44 & 1.65 & 1.99 & 2.07 & 2.71 & 3.299 \\
& Aksu & 1.49 & 1.99 & 2.32 & 2.58 & 2.89 & 3.637 \\
& Bayingol & 2.78 & 3.19 & 3.69 & 3.57 & 4.21 & 2.442
\end{tabular}

Table 2 Consumption of $\mathrm{N}$ fertilizers per unit area of cultivated land in 14 prefectures and cities of Xinjiang at different time periods from 1991 to 2015

\begin{tabular}{|c|c|c|c|c|c|c|c|}
\hline \multirow{2}{*}{ Region } & \multirow{2}{*}{ Prefecture/city } & \multicolumn{5}{|c|}{ Consumption of $\mathrm{N}$ fertilizers per unit area of cultivated land $\left(\mathrm{kg} / \mathrm{hm}^{2}\right)$} & \multirow{2}{*}{$\begin{array}{l}\text { Average annual } \\
\text { change rate } \\
(\%)\end{array}$} \\
\hline & & $1991-1995$ & $1996-2000$ & $2001-2005$ & $2006-2010$ & $2011-2015$ & \\
\hline Northern & Altay & 185 & 316 & 272 & 347 & 378 & 4.367 \\
\hline \multirow[t]{6}{*}{ Xinjiang } & Tacheng & 185 & 308 & 432 & 514 & 519 & 5.255 \\
\hline & Karamay & 218 & 237 & 189 & 347 & 482 & 6.271 \\
\hline & Bortala & 211 & 299 & 303 & 386 & 418 & 3.846 \\
\hline & Ili & 188 & 312 & 367 & 460 & 562 & 6.341 \\
\hline & Changji & 140 & 191 & 224 & 250 & 274 & 4.058 \\
\hline & Urumqi & 200 & 257 & 353 & 417 & 562 & 6.000 \\
\hline Eastern & Turpan & 151 & 165 & 172 & 201 & 297 & 4.409 \\
\hline Xinjiang & Hami & 152 & 204 & 205 & 248 & 324 & 4.344 \\
\hline Southern & Hotan & 186 & 271 & 253 & 252 & 263 & 2.690 \\
\hline \multirow[t]{4}{*}{ Xinjiang } & Aksu & 210 & 320 & 327 & 351 & 383 & 3.734 \\
\hline & Bayingol & 271 & 395 & 425 & 446 & 467 & 3.376 \\
\hline & Kashgar & 211 & 226 & 206 & 283 & 288 & 2.085 \\
\hline & Kizilsu & 241 & 270 & 264 & 315 & 316 & 2.391 \\
\hline \multicolumn{2}{|c|}{ Average } & 198 & 280 & 304 & 353 & 387 & 3.754 \\
\hline
\end{tabular}

As shown in Table 3, the significant climatic factors of WFV and their trends varied in different prefectures and cities. For example, although the annual average temperature increased across Xinjiang over the study period, the temperatures in Altay and Tacheng decreased slightly (Table 3). According to the results of correlation analysis, temperature, relative humidity, and sunshine hours were the primary factors influencing WFV in most prefectures and cities, followed by wind speed. Moreover, there was no significant correlation between WFV and climatic factors in Altay and Karamay. 
Table 3 Climatic factors significantly $(P<0.05)$ associated with water footprint of crop values (WFV) and their trends in 14 prefectures and cities of Xinjiang during the period 1991-2015

\begin{tabular}{|c|c|}
\hline Prefecture/city & Climatic factors \\
\hline Altay & - \\
\hline Tacheng & Sunshine hours (-) \\
\hline Karamay & - \\
\hline Bortala & Precipitation $(+)$; wind speed $(-)$ \\
\hline Ili & Wind speed $(+)$ \\
\hline Changji & Precipitation $(+)$; sunshine hours $(-)$; wind speed $(+)$ \\
\hline Urumqi & Sunshine hours $(+)$; relative humidity $(+)$ \\
\hline Turpan & Temperature $(+)$; relative humidity $(-)$ \\
\hline Hami & Sunshine hours $(+)$; relative humidity $(-)$ \\
\hline Hotan & Precipitation $(+)$; sunshine hours $(-)$; wind speed $(-)$ \\
\hline Aksu & Temperature $(+)$; relative humidity $(-)$ \\
\hline Bayingol & Temperature $(+)$; wind speed $(-)$ \\
\hline Kizilsu & Temperature $(+)$; sunshine hours $(+)$; relative humidity $(-)$ \\
\hline Kashgar & Sunshine hours (-) \\
\hline Average & Temperature $(+)$ \\
\hline
\end{tabular}

Note: "(+)" indicates an increase in the factor during the study period; "(-)" indicates a decrease in the factor over the study period; "-" indicates no significant variation trend.

\subsection{Influence of planting structure on WFV}

The area percentages of major crops cultivated in Xinjiang in 2015 were as follows: $34.34 \%$ for cotton, $18.72 \%$ for wheat, $14.53 \%$ for maize, $17.14 \%$ for fruits, $4.89 \%$ for vegetables, $3.30 \%$ for oil crops, $1.08 \%$ for soybean, $1.00 \%$ for rice, and $0.92 \%$ for sugar crops, which accounted for $95.92 \%$ of the total cultivated land area. Wheat and maize were the dominant grain crops while the most important economic crop was cotton. During the period 1991-2015, the proportion of fruits has grown rapidly and eventually became the second most important economic crop. As shown in Table 4 , WFV of cotton was the largest, while that of fruits and vegetables was significantly smaller as compared with other crops.

Table 4 Average WFV of major crops in Xinjiang during the period 1991-2015

\begin{tabular}{|c|c|c|c|c|c|c|c|c|c|}
\hline & Cotton & Wheat & Rice & Maize & Sugar crops & Soybean & Oil crops & Fruits & Vegetables \\
\hline $\begin{array}{c}\text { WFV } \\
\left(\mathrm{m}^{3} / \mathrm{CNY}\right) \\
\end{array}$ & 0.893 & 0.472 & 0.394 & 0.353 & 0.331 & 0.234 & 0.132 & 0.046 & 0.029 \\
\hline
\end{tabular}

The average SWUC in Xinjiang decreased from 1.17 to $1.08 \mathrm{~m}^{3} / \mathrm{CNY}$ in the $1990 \mathrm{~s}$, and then declined to $1.00 \mathrm{~m}^{3} / \mathrm{CNY}$ in 2011-2015 (Table 5). At the regional scale, the SWUC in most prefectures and cities in northern and eastern Xinjiang (except Karamay and Bortala) showed an effective downward trend. As of 2015, the SWUC values in all these prefectures or cities were controlled to less than $1.00 \mathrm{~m}^{3} / \mathrm{CNY}$. As exceptions, the SWUC values in Karamay and Bortala were significantly higher than those in other prefectures and cities. Moreover, Karamay is the only city with increasing SWUC during the study period. The SWUC values of the prefectures and cities in southern Xinjiang were quite similar at different time periods, with the values varying from 1.00 to $1.41 \mathrm{~m}^{3} / \mathrm{CNY}$, and generally higher than the average level in Xinjiang. Although the SWUC values in prefectures or cities in southern Xinjiang also showed a decreasing trend from 1991 to 2015, none of them had been limited below $1.00 \mathrm{~m}^{3} / \mathrm{CNY}$ as of 2015 . 
Table 5 Variations in the regional structural water-use coefficient (SWUC) in 14 prefectures and cities of Xinjiang at different time periods from 1991 to 2015

\begin{tabular}{cccccccc}
\hline \multirow{2}{*}{ Region } & Prefecture/city & \multicolumn{3}{c}{ SWUC ( $\left.\mathrm{m}^{3} / \mathrm{CNY}\right)$} & \multicolumn{2}{c}{$\begin{array}{c}\text { Average } \\
\text { annual change } \\
\text { rate }(\%)\end{array}$} \\
\cline { 3 - 7 } Northern & Altay & 0.95 & 0.89 & 0.62 & 0.59 & 0.54 & -0.031 \\
Xinjiang & Tacheng & 1.02 & 1.06 & 0.90 & 1.03 & 0.96 & -0.004 \\
& Karamay & 1.38 & 1.96 & 2.20 & 2.26 & 1.73 & 0.009 \\
& Bortala & 2.31 & 1.85 & 1.34 & 1.46 & 1.65 & -0.018 \\
& Ili & 0.59 & 0.57 & 0.61 & 0.62 & 0.61 & 0.003 \\
Eastern & Changji & 1.05 & 1.31 & 1.20 & 1.03 & 0.98 & -0.007 \\
Xinjiang & Urumqi & 0.76 & 0.97 & 1.08 & 1.04 & 0.61 & -0.010 \\
Southern & Turpan & 1.04 & 1.01 & 0.73 & 0.56 & 0.68 & -0.026 \\
Xinjiang & Hami & 0.91 & 0.85 & 0.53 & 0.40 & 0.41 & -0.048 \\
& Hotan & 1.11 & 1.29 & 1.07 & 1.00 & 1.02 & -0.008 \\
& Aksu & 1.22 & 1.33 & 1.09 & 1.21 & 1.19 & -0.003 \\
& Bayingol & 1.11 & 1.37 & 1.20 & 1.14 & 1.16 & -0.002 \\
& Kashgar & 1.25 & 1.27 & 1.18 & 1.21 & 1.04 & -0.013 \\
& Kizilsu & 1.21 & 1.41 & 1.22 & 1.02 & 1.00 & -0.008 \\
& Average & 1.08 & 1.17 & 1.04 & 1.02 & 1.00 & -0.006 \\
\hline
\end{tabular}

\subsection{Contribution rate analyses}

The growth in the agricultural machinery power and $\mathrm{N}$ fertilizer consumption contributed mightily to reducing WFV of planting industries in Xinjiang (Table 6). However, the contribution rates of different input factors among prefectures and cities exhibited obvious spatial heterogeneity.

Table 6 Contribution rates of influence factors to reduce WFV in Xinjiang during the period 1991-2015

\begin{tabular}{cccccccc}
\hline \multirow{2}{*}{ Region } & $\begin{array}{c}\text { Prefecture/ } \\
\text { city }\end{array}$ & $\begin{array}{c}\text { Agricultural } \\
\text { machinery } \\
\text { power }\end{array}$ & $\begin{array}{c}\text { Consumption } \\
\text { of } \\
\text { N fertilizers }\end{array}$ & $\begin{array}{c}\text { Planting } \\
\text { structure }\end{array}$ & $\begin{array}{c}\text { Climatic } \\
\text { factors }\end{array}$ & $\begin{array}{c}\text { Other factors } \\
\text { Standard } \\
\text { error }\end{array}$ \\
\hline Northern & Altay & 35.95 & 32.40 & 30.59 & - & 1.06 & 0.205 \\
Xinjiang & Tacheng & 40.39 & 50.28 & 5.49 & 3.06 & 0.78 & 0.086 \\
& Karamay & - & - & 63.09 & - & 36.91 & 0.293 \\
& Bortala & 25.19 & 39.01 & 17.18 & 27.71 & -9.09 & 0.209 \\
& Ili & 37.10 & 52.08 & - & 18.37 & -7.55 & 0.111 \\
Eastern & Changji & 14.59 & 43.73 & 0.10 & 24.42 & 17.15 & 0.193 \\
Xinjiang & Urumqi & 22.17 & 64.85 & - & 12.95 & 0.03 & 0.206 \\
Southern & Turpan & - & 36.65 & 22.75 & 17.19 & 23.41 & 0.224 \\
Xinjiang & Homi & - & 49.97 & 7.81 & 26.16 & 16.06 & 0.165 \\
& Hotan & 46.29 & 2.68 & 20.23 & 3.23 & 27.57 & 0.092 \\
& Aksu & 36.67 & 28.43 & - & 18.04 & 16.85 & 0.146 \\
& Bayingol & 32.41 & 32.67 & 4.06 & 15.70 & 15.16 & 0.151 \\
& Kashgar & 50.62 & 13.27 & 12.43 & 15.69 & 8.00 & 0.189 \\
& Kizilsu & 72.77 & 21.26 & 7.80 & 0.85 & -2.69 & 0.101 \\
\hline
\end{tabular}

Note: "-" indicates no significant correlation between WFV and influence factor.

Due to the rapid growth of agricultural machinery power used in southern Xinjiang, the contribution rates of agricultural machinery power to the reduction of WFV in most prefectures and 
cities in southern Xinjiang exceeded $50.00 \%$ (with an exception of Aksu) and even reached $74.35 \%$ in Kizilsu, which were much more significant than those in northern and eastern Xinjiang. On the contrary, the agricultural machinery development in northern Xinjiang was tardier than that in southern Xinjiang; as a result, the contribution rates of agricultural machinery to WFV in these regions were relatively low. The development of agricultural machinery power did not play a significant role in reducing WFV in eastern Xinjiang, as the investment of agricultural machinery power was almost unchanged over the past few decades.

The contribution rates of $\mathrm{N}$ fertilizer application to the reduction of WFV in all prefectures and cities in northern and eastern Xinjiang exceeded 30.00\%. However, in southern Xinjiang, only the Bayingol reached this level.

Significant regional differences were observed for the contribution rates of planting structures to WFV. For instance, neither agricultural investment nor climate change was the main factor affecting WFV variation in Karamay (Table 6). However, its worthy noting that changing process of WFV in Karamay (Fig. 2) was consistent with that of local SWUC (Table 5), and the change of SWUC contributed to $63.09 \%$ of the total change of WFV in this region. This result indicated that adjustment of planting structure may be the main factor driving WFV in Karamay, making the local planting industries to be more intensive in water consuming. In Altay, Turpan, Hotan, Bortala, and Kashgar, the contribution rates of planting structure to reduce WFV values were $30.59 \%, 22.75 \%, 20.23 \%$, $17.18 \%$, and $12.43 \%$, respectively, while those in the remaining prefectures and cities did not reached $10.00 \%$, demonstrating that planting structure adjustment in these regions have made notable contribution to agricultural water saving. Overall, the adjustion of planting structure in most prefectures and cities resulted in a reduction of WFV and improvement of AWUE.

Climatic factors did not exhibit significant impacts on WFV in Altay and Karamay while exhibited favorable impacts on agricultural water preservation in other prefectures and cities. WFV in Bortala, Changji, and Hami exhibited nonnegligible influences from climatic factors, with contribution rates greater than $20.00 \%$.

\section{Discussion}

\subsection{Correlation between WFV and SWUC}

There was an obvious correlation between the relative magnitude of WFV and the value of SWUC. That is, prefectures and cities with high SWUC were more likely to have large WFV, suggesting that planting structure might be one of the main factors controlling WFV. The three prefectures and cities with the lowest SWUC were Altay, Ili, and Urumqi, which are all located in northern Xinjiang. The cultivation percentages of cotton (with the high WFV) in these three prefectures and cities were relatively small, the grain crops were dominated by wheat and corn chronically, and the structure of economic crops was more diverse. In Altay, the major crops were soybeans and oil crops, while they were cotton and oil crops in Ili. Furthermore, soybeans, oil crops, cotton, vegetables, and fruits were all abundant in Urumqi. The diversification of economic crops planted and the increase in the cultivation percentages of crops with higher water-use efficiency primarily contributed to the reduction of local SWUC and the improvement of AWUE. In northern Xinjiang, both Karamay and Bortala were the important cotton production regions and had the large SWUC. The proportion of cotton cultivation in Karamay was only $8.1 \%$ in 1991 , but it rose to $96.3 \%$ in 2007 . In Bortala, the cultivation percentage of cotton increased from $33.8 \%$ in 1991 to $63.2 \%$ in 2008 , thereby directly contributing to the larger SWUC than those in other prefectures and cities.

The SWUC for the planting industries in Turpan and Hami exhibited a remarkable decreasing trend over time, which was attributed to the growing fruits industry. Fruit production became the largest planting industries in Turpan since 1999 and in Hami since 2005, which effectively improved the economic benefits of unit agricultural water use.

In southern Xinjiang, wheat and maize were the major grain crops and cotton was the major economic crop. Increases of the SWUC from 1991 to 2000 in this region were due to the increase in the proportion of cotton cultivation during this period. Subsequently, the cotton planting proportion 
essentially remained stable while the fruit planting significantly increased during 2006-2008, and this change in planting structure became the main driving force underlying the decline in the SWUC of the planting industries in southern Xinjiang.

The threaten of water shortage in agricultural production has stimulated researchers to pay more attention to comparing and evaluating water use efficiency of different crops (Zwart and Bastiaanssen, 2004; Fan et al., 2014). Furthermore, the influence of planting structure on AWUE is also getting more focus. Tan and Zheng (2019) indicated that due to planting structure adjustment, the economical efficiency of water use in the middle-reach region of Heihe River in China had increased by about 40.0\% from 2001 to 2012. Study of Kahramanoglu et al. (2019) showed that adjustment of the distribution of crops based on their water consumption is a practical solution of water saving and food security. Ma et al. (2020) discussed the agricultural water utilization policy from food yield priority and economic benefit priority based on the differences in crop types and food prices. Our research also proved that planting structure has a significant and even a decisive impact on AWUE in some areas. According to all these conclusions, it is inappropriate to discuss the influencing factors of AWUE without the consideration of planting structure at the theoretical level. In practical level, formulating local planting structure under comprehensive consideration of food security, economic benefits, water-saving effects and local condition is one of the feasible solutions to achieve sustainable development of agriculture in arid areas.

\subsection{Influence of climate factors on the WFV}

According to the results above mentioned, WFV in Bortala was distinctly higher than those in other prefectures and cities (Fig. 2), and it was greatly influenced by climatic factors. Bortala is located in a well-known windy area of Xinjiang (Wang and Sheng, 2011), suffering from a long-term intrusion by windy weather. The distinctive climate conditions have led to an apparently higher water footprint in the local planting industries. Fortunately, the wind speed has declined during the period 19912015 , resulting in a continuous reduction of crop water requirements. In addition, the apparent impacts of climatic factors on the WFV of planting industries in Changji and Hami were likely to be attributable to the increases of precipitation and sunshine hours.

\subsection{Driving forces of variations in planting structure}

According to the results of this research, agricultural input and planting structure are the main driving forces for the improvement of AWUE in different prefectures and cities of Xinjiang. So, what are the reasons for the changes in agricultural input and planting structure in Xinjiang? We infer that the spontaneous choice of farmers and the characteristics of natural conditions may be the possible reasons.

From the perspective of planting structure, in the early 1990s, agriculture in Xinjiang was mainly committed to solving the problem of food and clothing security. In 1991, the planting area of grains (including wheat, rice, and corn) accounted for $71.67 \%$ of the total cultivated area and it was decreased to only $39.92 \%$ in 2015 . It was declared that per capita food consumption in China was about $400 \mathrm{~kg} / \mathrm{a}$ (Tang et al., 2012), and the total grain consumption in Xinjiang in 2015 was about $9.54 \times 10^{6} \mathrm{t}$. With the total grain output of $20.22 \times 10^{6} \mathrm{t}$ in 2015 , Xinjiang can definitely meet its domestic food needs. As a consequence, motivations to cultivate economic crops for a higher economic benefit popularized. Since the 1990s, the cultivated proportions of economic crops dominated by cotton (cultivation percentage was 11.01\% in 1991 and $34.34 \%$ in 2015) and fruits (cultivation percentage was 4.68\% in 1991 and 17.14\% in 2015) have increased rapidly. The development of cotton planting industries is mainly attributed to the following reasons: (1) climatic conditions with sufficient light and heat; and (2) the abundant land resources that provide the sufficient space for the expansion of the cotton planting scale.

\subsection{Advantages of WFV}

Compared to the indicator AWUE, WFV effectively shows the composition of agricultural water use and clarifies the proportion of irrigation water in agricultural water consumption, which provides more accurate guidance for agricultural water management. In addition, based on the concept of WF, 
we expand the economic connotation of WFV, so that the AWUE of different crops can be directly integrated or compared, which solves the difficulty in rationally explaining the AWUE under complex planting structure and the quantitative description of the impact of planting structure on AWUE. In this research, the case study in Xinjiang has proved the availability of WFV.

\section{Conclusions}

The present study proposed an indicator of WFV and investigated the temporal and spatial variations of WFV in 14 prefectures or cities in Xinjiang from 1991 to 2015. Besides, the impacts of climate change, agricultural input, and planting structure adjustment on WFV were analyzed. The results showed that WFV in Xinjiang decreased from $0.293 \mathrm{~m}^{3} / \mathrm{CNY}$ in 1991 to $0.153 \mathrm{~m}^{3} / \mathrm{CNY}$ in 2015 , corresponding to an average annual change rate of $-3.532 \%$, reflecting a significant improvement in AWUE. WFV in 13 prefectures and cities, except that of Karamay, exhibited decreasing trends. However, the magnitude of decreases differed among prefectures and cities. The average SWUC in Xinjiang decreased from $1.08 \mathrm{~m}^{3} / \mathrm{CNY}$ in 1991 to $1.00 \mathrm{~m}^{3} / \mathrm{CNY}$ in 2015 . The variation process of SWUC was highly consistent with that of WFV in most prefectures and cities of Xinjiang, implying that planting structure was one of the primary factors affecting regional agricultural water-use efficiency. The results also demonstrated that the large-scale cultivation of cotton was the primary reason for the high SWUC value. Contribution rate analyses indicated that the comprehensive impact of human factors (including agricultural input and planting structure) on WFV was more significant in each prefecture or city than climatic factors.

\section{Acknowledgements}

This work was supported by the National Key Technology Research and Development Program of China (2017YFC0404301, 2016YFA0601602), the National Natural Science Foundation of China (51479209), the Application Foundation Research Project of Xinjiang Production and Construction Corps (2016AG003), and the Talent Initiate Scientific Research Project (RCZX2015027).

\section{References}

Aldaya M M, Munoz G, Hoekstra A Y. 2010. Water footprint of cotton, wheat and rice production in Central Asia. In: Value of Water Research Report Series Vol. 41. UNESCO-IHE Institute for Water Education. Delft, the Netherlands.

Apurupa G, Jeffrey J V, Lisa R W. 2019. Stomatal response in soybean during drought improves leaf-scale and field-scale water use efficiencies. Agricultural and Forest Meteorology, 276-277: 107629, doi: 10.1016/j.agrformet.2019.107629.

Bocchiola D, Nana E, Soncini A. 2013. Impact of climate change scenarios on crop yield and water footprint of maize in the Po valley of Italy. Agricultural Water Management, 116: 50-61.

Bulsink F, Hoekstra A Y, Booij M J. 2010. The water footprint of Indonesian provinces related to the consumption of crop products. Hydrology and Earth System Sciences, 14(1): 119-128.

Bureau of Statistics of Xinjiang Production and Construction Corps. 1991-2015. Xinjiang Production and Construction Corps Statistical Yearbook. Beijing: China Statistics Press. (in Chinese)

Bureau of Statistics of Xinjiang Uygur Autonomous Region. 1991-2015. Xinjiang Statistical Yearbook. Beijing: China Statistics Press. (in Chinese)

Calzadilla A, Rehdanz K, Tol R S J, et al. 2010. The economic impact of more sustainable water use in agriculture: A computable general equilibrium analysis. Journal of Hydrology, 384(3): 292-305.

Chapagain A K, Hoekstra A Y, Savenije H H G, et al. 2006. The water footprint of cotton consumption: An assessment of the impact of worldwide consumption of cotton products on the water resources in the cotton producing countries. Ecological Economics, 60(1): 186-203.

Chapagain A K, Orr S. 2009. An improved water footprint methodology linking global consumption to local water resources: A case of Spanish tomatoes. Journal of Environmental Management, 90(2): 1219-1228.

Chapagain A K, Hoekstra A Y. 2011. The blue, green and grey water footprint of rice from production and consumption perspectives. Ecological Economics, 70(4): 749-758.

Chen S Y, Shi Y Y, Guo Y Z, et al. 2010. Temporal and spatial variation of annual mean air temperature in arid and semiarid region in northwest China over a recent 46 year period. Journal of Arid Land, 2(2): 87-97. 
Chu Y M, Shen Y J, Yuan Z J, et al. 2017. Water footprint of crop production for different crop structures in the Hebei southern plain, North China. Hydrology and Earth System Sciences, 21(6): 3061-3069.

Du T S, Kang S Z, Zhang J H, et al. 2015. Deficit irrigation and sustainable water-resource strategies in agriculture for China's food security. Journal of Experimental Botany, 66(8): 2253-2269.

Fan Y B, Wang C G, Nan Z B. 2014. Comparative evaluation of crop water use efficiency, economic analysis and net household profit simulation in arid Northwest China. Agricultural Water Management, 146: 335-345.

Gilbert M, Hernandez M. 2019. How should crop water-use efficiency be analyzed? A warning about spurious correlations. Field Crops Research, 235: 59-67.

Hassan R M, Olbrich B. 1999. Comparative analysis of the economic efficiency of water use by plantation forestry and irrigation agriculture in the Crocodile River catchment. Agrekon, 38(4): 566-575.

He C Y, Huang G H, Liu L R, et al. 2020. Multi-dimensional diagnosis model for the sustainable development of regions facing water scarcity problem: A case study for Guangdong, China. Science of The Total Environment, 734: 139394, doi: 10.1016/j.scitotenv.2020.139394.

Hoekstra A Y, Hung P Q. 2002. Virtual water trade: a quantification of virtual water flows between nations in relation to international crop trade. In: Value of Water Research Report Series Vol. 11. UNESCO-IHE Institute for Water Education. Delft, the Netherlands.

Hoekstra A Y, Chapagain A K. 2008. Globalization of Water: Sharing the Planet's Freshwater Resources. Oxford: Blackwell Publishing, 1-208.

Hoekstra A Y, Chapagain A K, Aldaya M M, et al. 2009. Water Footprint Manual: State of the Art 2009. Enschede: Water Footprint Network Press, 1-127.

Howell T A. 2001. Enhancing water use efficiency in irrigated agriculture. Agronomy Journal, 93(2): 281-289.

Kahramanoglu I, Usanmaz S, Alas T. 2019. Water footprint and irrigation use efficiency of important crops in Northern Cyprus from an environmental, economic and dietary perspective. Saudi Journal of Biological Sciences, 27(1), doi: 10.1016/j.sjbs.2019.06.005.

Li Q H, Chen Y N, Shen Y J, et al. 2011. Spatial and temporal trends of climate change in Xinjiang, China. Journal of Geographical Sciences, 21(6): 1007-1018.

Li X S, Chen Z Z. 2010. Correctly using SPSS software for principal components analysis. Statistical Research, 27(8): 105-108. (in Chinese)

Lovarelli D, Bacenetti J, Fiala M. 2016. Water Footprint of crop productions: a review. Science of The Total Environment, 548-549: 236-251.

Lu Y, Zhang X Y, Chen S Y, et al. 2016. Changes in water use efficiency and water footprint in grain production over the past 35 years: a case study in the North China Plain. Journal of Cleaner Production, 116(1): 71-79.

Ma W J, Christian O, Yang D W. 2020. Spatiotemporal supply-demand characteristics and economic benefits of crop water footprint in the semi-arid region. Science of The Total Environment, 738: 139502, doi: 10.1016/j.scitotenv.2020.139502.

Ma X C, Karen A S, Pete W J. 2019. Performance of direct root-zone deficit irrigation on Vitis vinifera L. cv. Cabernet Sauvignon production and water use efficiency in semi-arid southcentral Washington. Agricultural Water Management, $221: 47-57$.

Marano R P, Filippi R A. 2015. Water Footprint in paddy rice systems. Its determination in the provinces of Santa Fe and Entre Ríos. Argentina. Ecological Indicators, 56: 229-236.

Mekonnen M M, Hoekstra A Y. 2010. A global and high-resolution assessment of the green, blue and grey water footprint of wheat. Hydrology and Earth System Sciences, 14(7): 17-23.

Mekonnen M M, Hoekstra A Y. 2014. Water footprint benchmarks for crop production: A first global assessment. Ecological Indicators, 46(11): 214-223.

Nana E, Corbari C, Bocchiola D. 2014. A model for crop yield and water footprint assessment: Study of maize in the Po valley. Agricultural Systems, 127: 139-149.

National Bureau of Statistics of China. 2015. Statistical Yearbook of China, Beijing: China Statistics Press. (in Chinese)

Pellegrini G, Ingrao C, Camposeo S, et al. 2016. Application of water footprint to olive growing systems in the Apulia region: a comparative assessment. Journal of Cleaner Production, 112(5): 2407-2418.

Piao S, Ciais P, Huang Y, et al. 2010. The impacts of climate change on water resources and agriculture in China. Nature, 467(7311): $43-51$.

Ridoutt B G, Pfister S. 2010. A revised approach to water footprint to make transparent the impacts of consumption and production on global freshwater scarcity. Global Environmental Change, 20(1): 113-120.

Rodriguez C I, Galarreta V A R D, Kruse E E. 2015. Analysis of water footprint of potato production in the pampean region of Argentina. Journal of Cleaner Production, 90: 91-96.

Sinclair T R, Tanner C B, Bennett J M. 1984. Water-use efficiency in crop production. Bioscience, 34(1): 36-40.

Sun S K, Wu P T, Wang Y B, et al. 2013a. The impacts of interannual climate variability and agricultural inputs on water footprint 
of crop production in an irrigation district of China. Science of The Total Environment, 444(2): 498-507.

Sun S K, Wu P T, Wang Y B, et al. 2013b. Temporal variability of water footprint for maize production: the case of Beijing from 1978 to 2008. Water Resources Management, 27(7): 2447-2463.

Sun S K, Wang Y B, Liu J, et al. 2016. Quantification and evaluation of water footprint of major grain crops in China. Journal of Hydraulic Engineering, 47(9): 1115-1124. (in Chinese)

Tao J, Yang D G. 2004. Analysis on factors of Xinjiang grain increase production in recent 50 years with principal components method. Arid Land Geography, 27(1): 95-99. (in Chinese)

Tan M H, Zheng L Q. 2019. Increase in economic efficiency of water use caused by crop structure adjustment in arid areas. Journal of Environmental Management, 230: 386-391.

Tang H J, Li Z M. 2012. Study on per capita grain demand based on Chinese reasonable dietary pattern. Scientia Agricultura Sinica, 45(11): 2315-2327. (in Chinese)

Wang F T, Yu C, Xiong L C, et al. 2019. How can agricultural water use efficiency be promoted in China? A spatial-temporal analysis. Resources, Conservation and Recycling, 145: 411-418.

Wang X, Sheng T Y. 2011. Study on the wind energy resources in Boertala prefecture. Journal of Anhui Agricultural Sciences, 39(22): 13653-313655. (in Chinese)

Wu Y F, Bake B, Zhang J S, et al. 2015. Spatio-temporal patterns of drought in North Xinjiang, China, 1961-2012 based on meteorological drought index. Journal of Arid Land, 7(4): 527-543.

Xu C C, Chen Y N, Yang Y H, et al. 2010. Hydrology and water resources variation and its response to regional climate change in Xinjiang. Journal of Geographical Sciences, 20(4): 599-612.

Yang Q, Zhu R X, Zhang J, et al. 2000. Mechanization profit portion estimation in plant products industry in Shaanxi Province. Transactions of the Chinese Society of Agricultural Engineering, 16(6): 64-67. (in Chinese)

Yoo S H, Choi J Y, Lee S H, et al. 2014. Estimating water footprint of paddy rice in Korea. Paddy \& Water Environment, 12(1): 4354.

Zahra Z, Karami E, Keshavarz M. 2020. Co-production of knowledge and adaptation to water scarcity in developing countries. Journal of Environmental Management, 262: 110283, doi: 10.1016/j.jenvman.2020.110283.

Zhao C F, Chen B, Hayat T, et al. 2014. Driving force analysis of water footprint change based on extended STIRPAT model: Evidence from the Chinese agricultural sector. Ecological Indicators, 47: 43-49.

Zwart S J, Bastiaanssen W G M. 2004. Review of measured crop water productivity values for irrigated wheat, rice, cotton and maize. Agricultural Water Management, 69(2): 115-133. 